University of Konstanz

Department of Economics

\title{
Disagreement, Uncertainty and the True Predictive Density
}

Fabian Krüger and Ingmar Nolte

Working Paper Series

2011-43

http://www.wiwi.uni-konstanz.de/workingpaperseries 


\title{
Disagreement, Uncertainty and the True Predictive Density*
}

\author{
Fabian Krüger ${ }^{\dagger}$ \\ University of Konstanz \\ CoFE
}

\author{
Ingmar Nolte $\ddagger$ \\ University of Warwick \\ FERC, CoFE
}

September 1, 2011

\begin{abstract}
This paper generalizes the discussion about disagreement versus uncertainty in macroeconomic survey data by emphasizing the importance of the (unknown) true predictive density. Using a forecast combination approach, we ask whether crosssections of survey point forecasts help to approximate the true predictive density. We find that although these cross-sections perform poorly individually, their inclusion into combined predictive densities can significantly improve upon densities relying solely on time series information.
\end{abstract}

JEL classification: C53, C83, E.7, F.7

Keywords: Disagreement, Uncertainty, Predictive Density, Forecast Combination

${ }^{*}$ We would like to thank Michael Clements, Holger Dette, Nikolaus Hautsch, Sandra Nolte, Winfried Pohlmeier, Ruben Seiberlich and Kenneth Wallis as well as the participants of the faculty seminar at Humboldt Universität zu Berlin, the second Humboldt-Copenhagen Conference in Financial Econometrics, and the 65th European Meeting of the Econometric Society for helpful comments. Skilled research assistance by Horatio Cuesdeanu is gratefully acknowledged. All remaining errors are ours.

${ }^{\dagger}$ Department of Economics, Box 124, University of Konstanz, 78457 Konstanz, Germany. Phone +49 7531 883753, Fax -4450, email: Fabian.Krueger@uni-konstanz.de. Financial support from the Fritz Thyssen foundation through the project "Analysis, Modeling and Prediction of Multivariate Volatility Processes" is gratefully acknowledged.

${ }^{\ddagger}$ Warwick Business School, Financial Econometrics Research Centre (FERC), University of Warwick, CV4 7AL, Coventry, United Kingdom. Phone +44-24-765-72838, Fax -23779, email: Ingmar.Nolte@wbs.ac.uk. 


\section{Introduction}

Decision making requires - beyond plain point forecasts - information about the uncertainty surrounding future events 1 In economics, surveys among experts have been an important source used for constructing measures of uncertainty.

Following the seminal article by Zarnowitz and Lambros (1987), the last decades have witnessed an extensive debate on how to best measure predictive uncertainty from expert surveys. In response to this challenge, the recent literature tends to construct variances from predictive histogram 2 which contain subjective probabilities of the target quantity falling into each of several histogram bins. An additional concept discussed in the literature is "disagreement", computed as the cross-sectional variance of experts' point forecasts. While Mankiw, Reis, and Wolfers (2003) discuss economic implications of disagreement per se, a number of studies (e.g. Bomberger (1996), Giordani and Söderlind (2003), Boero, Smith, and Wallis (2008) and Lahiri and Sheng (2010)) analyze whether disagreement can serve as a proxy for uncertainty. Thereby, the benchmark measure of uncertainty is typically constructed from predictive histograms.

Two major assumptions (often implicitly made) underlie the current debate: i) uncertainty is to be measured by second moments and ii) these second moments are best constructed from predictive histograms which are perceived to represent the true predictive density.

Both assumptions are unrealistic. First, abstracting from a pure mean-variance utility concept, alternative uncertainty measures such as quantiles, ranges, number of modi and stochastic dominance considerations are important for forecast users. Second, it is by no means clear (see Giordani and Söderlind (2003)) how to convert predictive histograms into a single variance-based measure of predictive uncertainty. Exemplary issues include the question of whether to take the average of variances constructed from individual-level histograms or the variance of an aggregate histogram, the design of the histogram bins as well as the predictive distribution within each bin.

Moreover, it seems unnecessarily restrictive to rely only on surveys as a single data source, since i) information from historical time series data can readily be added in a forecast combination setting (Wallis (2005)) and ii) the existence of a single superior approximation to

\footnotetext{
${ }^{1}$ Throughout this paper, and following the literature on macroeconomic survey data, we use the terms "uncertainty" and "risk" synonymously.

${ }^{2}$ For example, predictive histograms are available at the level of individual survey participants in the USbased Survey of Professional Forecasters (SPF). Also, the Bank of England's Survey of External Forecasters publishes an aggregate predictive histogram.
} 
the true data-generating process appears unlikely, especially in the presence of structural breaks (Aiolfi, Capistrán, and Timmermann (2011)). Recent studies by Kascha and Ravazzolo (2010), Jore, Mitchell, and Vahey (2010) and Geweke and Amisano (2011) highlight the success of combining probabilistic forecasts, thereby generalizing findings from the literature on the combination of point forecasts (see Timmermann (2006) for a survey).

This paper analyzes whether the cross-sectional distribution of experts' point forecasts helps to approximate the true predictive densities of several US macroeconomic variables. If this is the case, then cross-sections of survey point forecasts are informative about "predictive uncertainty", in a precise sense and independently of the specific uncertainty measure employed by the forecast user. This question generalizes the debate on "uncertainty" versus "disagreement" along two dimensions: First, rather than focussing on the predictive variance as one specific measure of uncertainty, we consider an entire predictive distribution. Based on this predictive distribution, any desired measure of uncertainty can be constructed. Second, we analyze the information content of the entire cross-sectional distribution of experts' point forecasts, rather than "disagreement" as one specific characteristic of this distribution.

We tackle our research question in a forecast combination setting. Specifically, we construct estimates of the cross-sectional distribution of experts' point forecasts in two distinct survey data sets: The SPF data which contains quantitative forecasts, and the Financial Market Survey administered by the ZEW ("Centre of European Economic Research") containing qualitative forecasts of several US macroeconomic variables. Although qualitative forecasts convey less information than quantitative ones, they may be more reliable as they require less sophistication from survey participants 3 We ask whether the cross-sectional distributions of point forecasts can add information to predictive densities obtained from three different time series models. These models are specifically chosen to capture a wide range of data sources and functional form assumptions, with the aim of creating a fairly tough benchmark setting for the survey data. We then analyze whether combined predictive densities including survey information lie significantly closer to the true predictive density than combined predictive densities solely relying on time series information.

Closeness to the true predictive density is defined and understood in a Maximum Likelihood sense. Hence, forecasts are evaluated by the log score criterion, which has the property that it is uniquely maximized by the true predictive density. Thus, the goal of finding the true predictive density is equivalent to the maximization of the expected log score.

\footnotetext{
${ }_{3}^{3}$ See Manski (2004) for a careful discussion of topics related to the measurement and interpretation of survey expectations.
} 
The rest of this paper is organized as follows. Section 2 introduces our combination setting, Section 3 presents all individual survey- and time series models, Section 4 presents empirical results, and Section 5 concludes.

\section{Model Setup and Data}

Let $Y_{t}, t=1, \ldots, T$ denote the stationary transform of a macroeconomic variable sampled at quarterly frequency and $\mathcal{F}_{t}$ the true information process. We are interested in the true two-quarter ahead 4 predictive density $f_{t}\left(Y_{t+2}\right) \equiv f_{t}\left(Y_{t+2} \mid \mathcal{F}_{t}\right)$ which is usually unavailable since both the information set $\mathcal{F}_{t}$ and the true functional form $f_{t}(\cdot)$ are unknown. What we observe in reality are several incomplete information sets $\mathcal{F}_{t}^{j} \subset \mathcal{F}_{t}, j=1, \ldots, J$ on which we rely to specify $J$ individual predictive densities $f_{t}^{j}\left(Y_{t+2}\right) \equiv f_{t}^{j}\left(Y_{t+2} \mid \mathcal{F}_{t}^{j}\right)$. These may differ in both their underlying information sets and their functional form assumptions; in particular, we will later distinguish between survey- and time series information. In addition, we consider combined predictive densities of the form $f_{t}^{C}\left(Y_{t+2}\right) \equiv f_{t}^{C}\left(Y_{t+2} \mid \mathcal{F}_{t}^{1}, \ldots, \mathcal{F}_{t}^{J}\right)$.

The specification of a loss function $g(\cdot)$ which expresses the forecast user's utility from the combination of a generic density forecast $\tilde{f}_{t}\left(Y_{t+2}\right)$ and an ex-post realized outcome $y_{t+2}$ is essential to our study. A wide range of loss functions have been suggested in the literature; see e.g. Winkler (1996), Gneiting and Raftery (2007) as well as Boero, Smith, and Wallis (2010). We use the log score criterion (Good (1952)) given by $g\left(y_{t+2} ; \tilde{f}_{t}\left(Y_{t+2}\right)\right)=$ $\ln \left(\tilde{f}_{t}\left(y_{t+2}\right)\right)$ which is the logarithmic value of the predictive density at the ex-post realized outcome. The log score is conceptually related to Maximum Likelihood and the familiar Kullback and Leibler (1951) distance.

The expected log score of a candidate predictive density $\tilde{f}_{t}\left(Y_{t+2}\right)$ is given by

$$
\mathrm{E}\left[\ln \left(\tilde{f}_{t}\left(Y_{t+2}\right)\right) \mid \mathcal{F}_{t}\right]=\int_{\mathbb{R}} \ln \left(\tilde{f}_{t}\left(Y_{t+2}\right)\right) f_{t}\left(Y_{t+2}\right) d Y_{t+2}
$$

The Kullback and Leibler (1951) distance between the true predictive density $f_{t}\left(Y_{t+2}\right)$ and its approximation $\tilde{f}_{t}\left(Y_{t+2}\right)$ is given by

\footnotetext{
${ }^{4}$ We consider two-quarter ahead predictions since this forecast horizon is covered by both the SPF- and ZEW surveys.
} 


$$
\begin{aligned}
\operatorname{KL}\left(f_{t}, \tilde{f}_{t}\right) & =\mathrm{E}\left[\ln \left[\frac{f_{t}\left(Y_{t+2}\right)}{\tilde{f}_{t}\left(Y_{t+2}\right)}\right] \mid \mathcal{F}_{t}\right] \\
& =\int_{\mathbb{R}} \ln \left(f_{t}\left(Y_{t+2}\right)\right) f_{t}\left(Y_{t+2}\right) d Y_{t+2}-\int_{\mathbb{R}} \ln \left(\tilde{f}_{t}\left(Y_{t+2}\right)\right) f_{t}\left(Y_{t+2}\right) d Y_{t+2} .
\end{aligned}
$$

Since the first term in (3) does not depend on $\tilde{f}_{t}$, it is irrelevant for the task of choosing a good predictive density. Hence, maximizing the expected log score is tantamount to minimizing the Kullback and Leibler (1951) distance to the unknown true predictive density $f_{t}\left(Y_{t+2}\right)$. The (unique) minimum of $\operatorname{KL}\left(f_{t}, \tilde{f}_{t}\right)$ (and hence, the unique maximum of the expected $\log$ score) is attained by setting $\tilde{f}_{t}(\cdot)=f_{t}(\cdot)$; in this case, $\operatorname{KL}\left(f_{t}, f_{t}\right)=05$ This establishes that the log score is a "proper" scoring rule: a forecaster wishing to maximize the expected log score cannot do better than revealing what he thinks is the true predictive density $f_{t}(\cdot)$ (Winkler (1969)).

Clearly, the expected log score in (1) is unobservable in practice. Instead, the predictive density $f_{t}^{j}$ is commonly evaluated on the basis of the realized log scores $\left\{\ln \left(f_{t}^{j}\left(y_{t+2}\right)\right)\right\}_{t=T_{c}}^{T-2}$ corresponding to the evaluation sample $y_{T_{c}+2}, \ldots, y_{T}$ defined below, where $T_{c}<T$. The negative of the $\log$ score, $-\ln \left(f_{t}^{j}\left(y_{t+2}\right)\right)$, is the loss of model $f^{j}$ at time $t+2$. The corresponding sequence of loss differentials between model $f^{j}$ and a competing model $f^{k}$ is given by $\left\{d_{t+2}^{j, k}\right\}_{t=T_{c}}^{T-2}$, where

$$
d_{t+2}^{j, k} \equiv \ln \left(f_{t}^{k}\left(y_{t+2}\right)\right)-\ln \left(f_{t}^{j}\left(y_{t+2}\right)\right) .
$$

Such sequences of loss differentials directly allow for statistical comparisons of the predictive accuracy of two or more competing models via tests in the spirit of Diebold and Mariano (1995, henceforth, DM) and Hansen (2005), respectively; see Kascha and Ravazzolo (2010) and Bao, Lee, and Saltoglu (2007) for two exemplary applications.

Our empirical study uses information sets of different origins; we specify five models to estimate predictive densities on the basis of these information sets. The first two models are based on survey information, while the last three models are based on time series information. In our analysis, the latter models will serve (individually and in combined form) as benchmark predictive densities. The question we address is whether they can be significantly improved upon via combination with survey information. Our choice of time series based predictive densities is guided by the idea of spanning a wide range of data

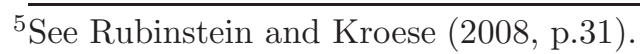


sources and functional form assumptions. This should render it fairly tough for the survey based densities to add further information.

The first model is developed around the SPF currently administered by the Federal Reserve Bank of Philadelphia. The survey provides two-quarter ahead point forecasts of important macroeconomic aggregates, at the individual forecaster level (roughly 30-40 participants per period) 6 We employ a nonparametric estimate of the cross-sectional distribution of point forecasts to obtain a predictive density. The second model exploits the ZEW Financial Market Survey which contains individual-level forecasts of roughly 300 finance professionals in qualitative form 7 We use the Carlson and Parkin (1975) quantification method to estimate the cross-sectional distribution of point forecasts which we again interpret as a predictive density. The third model is based on past observations of the target variable $Y_{t+2}$. We construct a predictive density from a nonparametric estimate of the distribution of $Y_{t+2}$, conditional on the single predictor $Y_{t}$. Models number four and five are based on a rich set of approximately 100 macroeconomic predictors, in addition to observations from the target variable. Model four is based on the idea of constructing a density forecast for $Y_{t+2}$ from forecasts of a number of different conditional quantiles of $Y_{t+2}$ (Koenker (2005)). As predictors in each of the conditional quantile regressions, we use the most recent value $Y_{t}$ of the target variable as well as principal components summarizing the macroeconomic predictors at time $t$ (Stock and Watson (2002)). Model five uses the same set of regressors to construct a point forecast of $Y_{t+2}$ and uses the assumption that forecast errors are normally distributed. We provide a more detailed description of all models in the next section.

We consider predictive densities for four quarterly macroeconomic aggregates from the US: The annualized growth rate of real GDP, the annualized CPI inflation rate, the three-month TBILL rate, and the ten-year TBOND rate 8 The data we use range from 1964/4 to 2009/4; the sample paths of the four variables during this time span are depicted in Figure 1 below. In order to mimic the process of producing and combining forecasts in real time, we split our data into three subsamples: First, observations until $T_{e}$ ("estimation sample") are used to estimate the parameters of the individual predictive densities. Second, observations between $T_{e}+2$ and $T_{c}$ ("combination sample") are used to estimate unknown parameters

\footnotetext{
${ }^{6}$ See http://www.philadelphiafed.org/research-and-data/real-time-center/survey-of-professional-forecasters/ for detailed information about the SPF.

${ }^{7}$ Nolte and Pohlmeier (2007) and Nolte, Nolte, and Pohlmeier (2010) provide detailed data descriptions.

${ }^{8}$ All data were downloaded from the FRED database administered by the Federal Reserve of St. Louis. We compute the GDP growth rate as $Y_{t}=\ln \left(X_{t}\right)-\ln \left(X_{t-1}\right)$, where $X_{t}$ is the quarterly level of real GDP. Finally, we annualize this growth rate. For inflation, we first compute quarterly levels of the CPI index by averaging across three monthly observations. We then compute annualized quarterly growth rates as described for GDP above. For both interest rates, we obtain quarterly levels by averaging over the rates corresponding to all working days during the quarter.
} 
of the combined predictive densities. Third, all combined and individual out-of sample density forecasts are finally evaluated using observations between $T_{c}+2$ and $T$ ("evaluation sample"). We initially set $T_{e}$ to $1992 / 1$ and $T_{c}$ to $1999 / 49$ We then shift both $T_{e}$ and $T_{c}$ in a rolling window fashion, such that the estimation sample always contains $R=110$ observations and the combination sample always contains $W=30$ observations. At the end of our forecasting exercise, we have thus produced 39 combined out-of sample density forecasts for observations occurring between 2000/2 and 2009/4. These forecasts form the basis for our comparison of the (individual and combined) models' relative predictive performance.

GDP

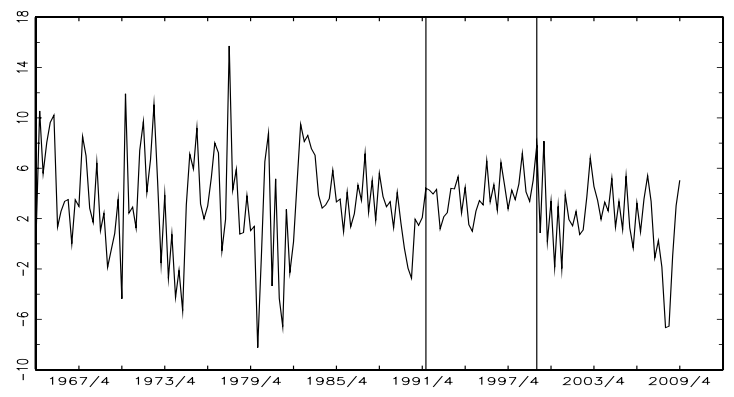

TBILL

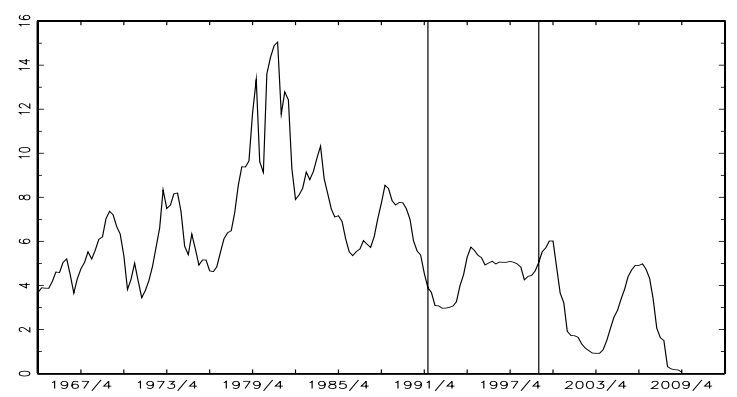

CPI

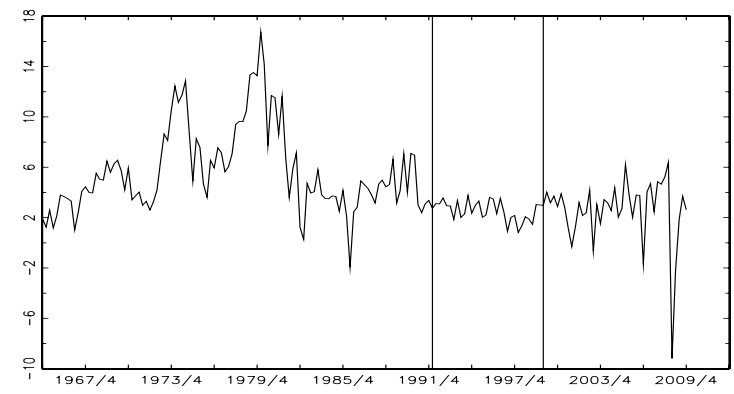

TBOND

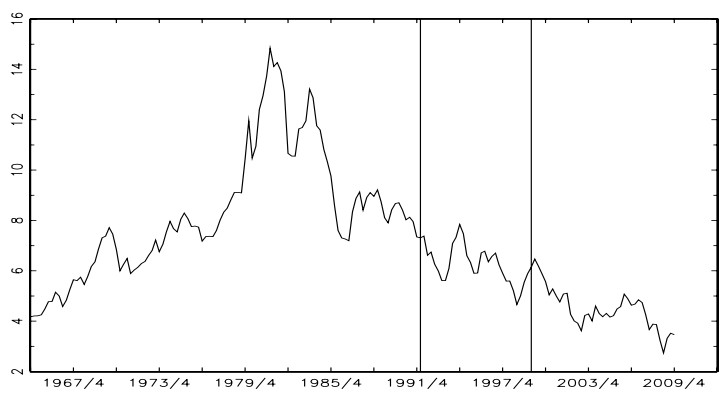

Figure 1: Sample paths of the annualized growth rate of real GDP, the annualized CPI inflation rate, the three-month TBILL rate and the ten-year TBOND rate between 1964/4 and 2009/4. The left vertical line marks 1992/1, the end of our estimation sample in the first forecast recursion. The right vertical line marks 1999/4, the end of our combination sample in the first forecast recursion.

${ }^{9}$ Our choice of $T_{e}$ is determined by the availability of the ZEW forecasts. 


\section{Individual Predictive Densities}

\subsection{Approaches Based on Survey Data}

The first two approaches are based on the idea of interpreting the (estimated) cross-sectional distribution of point forecasts of $Y_{t+2}$ among a specific group of experts as an approximation to the true predictive density $f_{t}\left(Y_{t+2} \mid \mathcal{F}_{t}\right)$. We implement two distinct variants which rely on two different surveys: First, a nonparametric estimate of the cross-sectional distribution of forecasts among SPF participants. Second, a parametric quantification method based estimate for the qualitative forecasts of the ZEW Financial Market Survey.

\section{Model 1: Survey forecast based on SPF data}

Let $y_{i t+2}^{1}$ be the point prediction expressed by the $i$ th SPF participant in period $t$, with $i \in\left\{1, \ldots, N_{t}^{1}\right\}$. Superindex " 1 " expresses that a quantity refers to model 1 ; similar notation is used in the following whenever an analogous quantity appears in several models. We neglect the identities of the forecasters and view the $N_{t}^{1}$ different forecasts as independent draws from the cross-sectional distribution of forecasts of $Y_{t+2}$ based on time $t$; this distribution can be thought of as representing the range of expectations about $Y_{t+2}$ among the SPF participants. We then use a nonparametric estimate of this distribution as a predictive density.

Formally, we have

$$
f_{t}^{1}\left(Y_{t+2}\right)=\frac{1}{N_{t}^{1} h_{t}^{1}} \sum_{i=1}^{N_{t}^{1}} K\left(\frac{Y_{t+2}-y_{i t+2}^{1}}{h_{t}^{1}}\right),
$$

where $h_{t}^{1}$ is the bandwidth and $K(\cdot)$ is the kernel used for our nonparametric estimate of the cross-sectional distribution of expert forecasts. We employ a Gaussian kernel and choose the bandwidth $h_{t}^{1}$ by the rule of thumb due to Silverman (1986).

\section{Model 2: Survey forecast based on ZEW data}

Unlike the SPF forecasts, the ZEW forecasts are qualitative. Rather than a quantitative prediction $y_{i t+2}^{2}$, we thus observe three dummy variables $\left(u_{i t+2}, s_{i t+2}, d_{i t+2}\right)$ ("up/ same/ down") which code the forecast of the $i$ th survey participant, with $i \in\left\{1, \ldots, N_{t}^{2}\right\}$. The Carlson and Parkin (1975) method 10 assumes the following relationship between latent

\footnotetext{
${ }^{10}$ See Pesaran and Weale (2006) for a discussion and Nolte and Pohlmeier (2007) for an application to the ZEW data.
} 
continuous and observed directional quantities:

$$
\left(u_{i t+2}, s_{i t+2}, d_{i t+2}\right) \equiv \begin{cases}(1,0,0) & y_{i t+2}^{2} \geq \lambda_{u t+2} \\ (0,1,0) & \lambda_{d t+2} \leq y_{i t+2}^{2}<\lambda_{u t+2} \\ (0,0,1) & y_{i t+2}^{2}<\lambda_{d t+2}\end{cases}
$$

where $\lambda_{d t+2}<\lambda_{u t+2}$ are the respective down and up threshold series.

Carlson and Parkin (1975) assume that the cross-section of latent quantitative forecasts made at time $t$ is drawn from a normal distribution: $y_{i t+2}^{2} \sim N\left(\mu_{t+2}, \sigma_{t+2}^{2}\right)$. Computing the individual level "up" and "down" probabilities and replacing them by their sample counterparts yields:

$$
\begin{aligned}
& u_{t+2}=1-\Phi\left(\frac{\lambda_{u t+2}-\mu_{t+2}}{\sigma_{t+2}}\right), \\
& d_{t+2}=\Phi\left(\frac{\lambda_{d t+2}-\mu_{t+2}}{\sigma_{t+2}}\right),
\end{aligned}
$$

where $u_{t+2} \equiv \frac{1}{N_{t}^{2}} \sum_{i=1}^{N_{t}^{2}} u_{i t+2}$ and $d_{t+2} \equiv \frac{1}{N_{t}^{2}} \sum_{i=1}^{N_{t}^{2}} d_{i t+2}$ denote the cross-sectional shares of "up" and "down" forecasts recorded at time $t, N_{t}^{2}$ is the corresponding number of micro-level forecasts and $\Phi(\cdot)$ denotes the cumulative density function (cdf) of the standard normal distribution.

$\left(\mu_{t+2}, \sigma_{t+2}^{2}\right)$ are identified from (5) and (6) only under the assumption that the thresholds $\lambda_{d t+2}$ and $\lambda_{u t+2}$ are known. Therefore, we use threshold series based on individual-level responses to an additional questionnaire sent out by the ZEW from time to time. Having estimated $\mu_{t+2}$ and $\sigma_{t+2}^{2}$ in this way, we construct an estimate of the cross-sectional distribution of point forecasts among the ZEW survey participants, based on the Carlson and Parkin (1975) assumptions.

\subsection{Approaches Based on Time Series Data}

In addition to the survey-based predictive densities we consider three different approaches based on time series data. 


\section{Model 3: Nonparametric conditional density estimation}

Our third predictive density is a nonparametric estimate of the conditional distribution of $Y_{t+2}$ given $Y_{t}$, evaluated at the most recently observed value $y_{t} 11$ Formally, we have

$$
\begin{aligned}
f_{t}^{3}\left(Y_{t+2}\right) & =\hat{f}\left(Y_{t+2} \mid Y_{t}=y_{t}\right)=\frac{\hat{f}\left(Y_{t+2}, y_{t}\right)}{\hat{f}\left(y_{t}\right)} \\
\hat{f}\left(Y_{t+2}, Y_{t}\right) & =\frac{1}{R\left(h_{t}^{3}\right)^{2}} \sum_{j=0}^{R-1} K\left(\frac{Y_{t+2}-y_{t-j}}{h_{t}^{3}}\right) K\left(\frac{Y_{t}-y_{t-j-2}}{h_{t}^{3}}\right), \\
\hat{f}\left(Y_{t}\right) & =\frac{1}{R h_{t}^{3}} \sum_{j=0}^{R-1} K\left(\frac{Y_{t}-y_{t-j}}{h_{t}^{3}}\right) .
\end{aligned}
$$

Estimation of $f_{t}^{3}\left(Y_{t+2}\right)$ is performed using a rolling window of $R=110$ quarterly observations. As for Model 1, we use a Gaussian kernel $K(\cdot)$; we select the bandwidth $h_{t}^{3}$ via Scott's rule (Härdle, Müller, Sperlich, and Werwatz (2004, p.73)).

\section{Model 4: Quantile regression}

Our fourth predictive density is based on two-step ahead forecasts $q_{\alpha t}\left(Y_{t+2}\right)$ of the $\alpha$ quantile of $Y_{t+2} .12$

$$
q_{\alpha t}\left(Y_{t+2}\right)=\hat{\beta}_{\alpha 0}+\hat{\beta}_{\alpha 1} y_{t}+\hat{\beta}_{\alpha 2} p c_{t}
$$

where $\alpha \in(0,1)$ and $p c_{t}$ is the first principal component extracted from a set of 92 stationary macroeconomic predictors; see the Appendix for a description of all underlying variables and their transformations and Stock and Watson (2002) for a classic reference on macroeconomic forecasting using principal components.

The estimated parameter vector $\hat{\beta}_{\alpha}=\left[\hat{\beta}_{\alpha 0}, \hat{\beta}_{\alpha 1}, \hat{\beta}_{\alpha 2}\right]^{\prime}$ in (8) is given by

$$
\hat{\beta}_{\alpha}=\underset{b \in \mathbb{R}^{3}}{\operatorname{argmin}} \sum_{j=0}^{R-1}\left(y_{t-j}-x_{t-j-2}^{\prime} b\right)\left(\alpha-\mathbf{1}\left(y_{t-j}-x_{t-j-2}^{\prime} b<0\right)\right),
$$

\footnotetext{
${ }^{11} \overline{\text { See Härdle, Müller, Sperlich, and Werwatz }}$ (2004, Section 3.6) for a textbook treatment of multivariate density estimation.

${ }^{12}$ The idea of constructing a predictive density from quantile regressions has been pursued by Cenesizoglu and Timmermann (2008) and Coroneo and Veredas (2010). See Komunjer (2005) for a treatment of the statistical properties of regression quantiles in a time series context.
} 
where $x_{t}=\left[\begin{array}{lll}1 & y_{t} & p c_{t}\end{array}\right]^{\prime}$ and $\mathbf{1}(\cdot)$ is the indicator function. As for Model 3 above, we use a rolling window of $R=110$ quarterly observations for parameter estimation and construction of the principal component $p c_{t}$.

In principle, we could estimate quantile regressions for a fine grid of levels $\alpha$ and construct a predictive histogram directly from the resulting predictions $q_{\alpha t}\left(Y_{t+2}\right)$ in (8) . However, this approach would be problematic for a number of reasons: First, the predicted quantiles $q_{\alpha t}\left(Y_{t+2}\right)$ do not necessarily satisfy the logical requirement of monotonicity in $\alpha$, especially if we consider a fine grid of values for $\alpha 13$ Second, since the different quantile levels are treated in isolation, the predictions $q_{\alpha t}\left(Y_{t+2}\right)$ are an implausibly rough function of $\alpha$. Third, the predicted "tail quantiles" ( $\alpha$ near zero or one) are very unreliable due to our small sample size typical of macroeconomic time series.

In order to resolve the first two problems, we proceed as follows: We first obtain predicted quantiles $q_{\alpha t}\left(Y_{t+2}\right)$ for a fine grid of values $\alpha \in\{0.005,0.01, \ldots, 0.995\}$. We then run a local linear regression of $q_{\alpha t}\left(Y_{t+2}\right)$ on the quantile level $\alpha$, subject to the constraint that the resulting prediction $\tilde{q}_{\alpha t}\left(Y_{t+2}\right)$ be strictly increasing in $\alpha$. We implement the procedure of Dette, Neumeyer, and Pilz (2006) for this purpose. This provides us with a new sequence of predicted quantiles $\tilde{q}_{\alpha t}\left(Y_{t+2}\right)$ which is both smooth and monotone in $\alpha$. In order to resolve the third problem, we impose normality on the predicted quantiles at levels $\alpha$ smaller than 0.05. This is achieved by equalizing these quantiles to the quantiles of a normally distributed variable with mean $\tilde{q}_{0.5 t}\left(Y_{t+2}\right)$ and standard deviation chosen to match $\tilde{q}_{0.05 t}\left(Y_{t+2}\right)$. We proceed analogously for quantiles at levels $\alpha$ exceeding 0.95 .

To summarize, our transformed quantile predictions $q_{\alpha t}^{*}\left(Y_{t+2}\right)$ are given by

$$
q_{\alpha t}^{*}\left(Y_{t+2}\right)= \begin{cases}\tilde{q}_{0.5 t}\left(Y_{t+2}\right)+\frac{\tilde{q}_{0.05 t}\left(Y_{t+2}\right)-\tilde{q}_{0.5 t}\left(Y_{t+2}\right)}{\Phi^{-1}(0.05)} \Phi^{-1}(\alpha) & \alpha<0.05 \\ \tilde{q}_{\alpha t}\left(Y_{t+2}\right) & \alpha \in[0.05,0.95], \\ \tilde{q}_{0.5 t}\left(Y_{t+2}\right)+\frac{\tilde{q}_{0.95 t}\left(Y_{t+2}\right)-\tilde{q}_{0.5 t}\left(Y_{t+2}\right)}{\Phi^{-1}(0.95)} \Phi^{-1}(\alpha) & \alpha>0.95\end{cases}
$$

where $\Phi^{-1}(\cdot)$ denotes the inverse of the cdf of the standard normal distribution. We finally obtain the predictive density $f_{t}^{4}\left(Y_{t+2}\right)$ by constructing a histogram from the transformed quantile predictions $q_{\alpha t}^{*}\left(Y_{t+2}\right)$ at levels $\alpha \in\{0.05,0.1, \ldots, 0.95\}$ and imposing normality on the tails as discussed above.

\footnotetext{
${ }^{13}$ This phenomenon, which is often referred to as "quantile crossing", is well known in the literature; see e.g. Dette and Volgushev (2008) and the references therein.
} 


\section{Model 5: Parametric distribution around a mean forecast}

For the fifth predictive density, we construct a parametric mean forecast and then impose a specific distributional assumption (normality) on the prediction errors. Specifically, we have

$$
\begin{aligned}
\hat{\mu}_{t+2} & =\hat{\gamma}_{0}+\hat{\gamma}_{1} y_{t}+\hat{\gamma}_{2} p c_{t}, \\
\hat{\sigma}_{t+2} & =\sqrt{\frac{1}{R-1} \sum_{j=0}^{R-1}\left(y_{t-j}-x_{t-j-2}^{\prime} \hat{\gamma}\right)^{2}}, \\
f_{t}^{5}\left(Y_{t+2}\right) & =\frac{1}{\hat{\sigma}_{t+2}} \phi\left(\frac{Y_{t+2}-\hat{\mu}_{t+2}}{\hat{\sigma}_{t+2}}\right) .
\end{aligned}
$$

where $x_{t}=\left[\begin{array}{lll}1 & y_{t} & p c_{t}\end{array}\right]^{\prime}, \hat{\gamma}=\left[\begin{array}{lll}\hat{\gamma}_{0} & \hat{\gamma}_{1} & \hat{\gamma}_{2}\end{array}\right]^{\prime}, \phi(\cdot)$ denotes the probability distribution function of the standard normal distribution and $p c_{t}$ is as in Model 4 above. The parameter vector $\hat{\gamma}$ is estimated via OLS using a rolling window of $R=110$ observations.

\subsection{Discussion and Forecast Combinations}

The five models we consider differ with respect to both their underlying information sets and their functional form assumptions. This causes them to produce very different predictive distributions, in terms of location, dispersion, skewness, kurtosis and shape. While models two and five rest on restrictive normality assumptions, the other three models can generate asymmetric, fat-tailed and/or multimodal densities. Figures 2 and 3 display examples of all five predictive distributions, for i) the TBILL rate in the fourth quarter of 2000 and ii) the CPI inflation rate during the third quarter of 2008.

In addition to analyzing individual predictive densities, we consider forecast combinations as a natural next step to approximate the true predictive density. Moreover, to address the question whether the survey based densities contain incremental information, we will later consider combinations among different sets of models (time series information only versus time series- and survey information). Combination of point forecasts has a long and successful tradition in economics; see Timmermann (2006) for a survey. Combination of predictive densities has recently been pursued by Hall and Mitchell (2007), Geweke and Amisano (2011), Kascha and Ravazzolo (2010) and Jore, Mitchell, and Vahey (2010). In our study the individual predictive densities to be combined are very heterogeneous, spanning a wide range of data sources and functional form assumptions. We consider a number of 
combination approaches; all of them are based on the idea of specifying a mixture density

$$
\begin{aligned}
f_{t}^{C}\left(Y_{t+2}\right) & =\sum_{j=1}^{J} w_{t}^{j} f_{t}^{j}\left(Y_{t+2}\right), \\
w_{t}^{j} & \in[0,1] \\
\sum_{j=1}^{J} w_{t}^{j} & =1
\end{aligned}
$$

to combine the individual predictive densities (Wallis (2005)). We consider four standard ways of specifying the weights $w_{t}^{j}$ (see Kascha and Ravazzolo (2010)):

- Equal weights (E):

$$
w_{t}^{j}=\frac{1}{J}
$$

- Recursive log score weights (RLS):

$$
w_{t}^{j}=\frac{\exp \left(\sum_{l=0}^{W-1} \ln \left(f_{t-2-l}^{j}\left(y_{t-l}\right)\right)\right)}{\sum_{j=1}^{J} \exp \left(\sum_{l=0}^{W-1} \ln \left(f_{t-2-l}^{j}\left(y_{t-l}\right)\right)\right)},
$$

i.e. weights are chosen in proportion to the different models' track record during the last $W$ periods. We set $W=30$ in the following.

- Recursive best model (RB):

$$
w_{t}^{j}=\left\{\begin{array}{ll}
1 & \text { if } \left.j=\underset{k}{\operatorname{argmax}} \sum_{l=0}^{W-1} \ln \left(f_{t-2-l}^{k}\left(y_{t-l}\right)\right)\right) \\
0 & \text { else }
\end{array},\right.
$$

i.e. the model with the best track record during the last $W$ observations is selected.

- Optimal in-sample weights (OIS):

$$
w_{t}^{j}=\underset{\omega^{1}, \ldots, \omega^{J}}{\operatorname{argmax}} \sum_{l=0}^{W-1} \ln \left(\sum_{j=1}^{J} \omega^{j} f_{t-2-l}^{j}\left(y_{t-l}\right)\right),
$$

under the constraint that the $\omega^{j}$ are positive and sum to unity. This scheme amounts to a numerical search for the weight vector which maximizes the average log score for the last $W$ observations 14

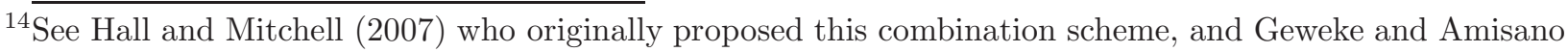
(2011) who provide a formal discussion.
} 
Note that the equal weights combination scheme provides insurance against idiosyncratic model failure. This is particularly effective if the predictive densities are heterogeneous, so that simultaneous failure of all models is unlikely. By contrast, the second and third combination schemes aim at dynamically switching between individual models, such as to emphasize successful over less successful predictive densities. Thereby, recursive log score weights constitute a less aggressive switching mechanism than the recursive best model selector. These schemes are promising if relative model performance is persistent, so that past relative performance is a good proxy for future relative performance. Optimal in-sample weights can, in principle, produce both balanced $\left(w_{t}^{j} \approx \frac{1}{J}\right)$ and unbalanced combination weights, depending on what performed better in the past. Once again, however, some degree of stability in relative model performance is required to justify the implicit notion that historically successful combination weights will perform well in the future.
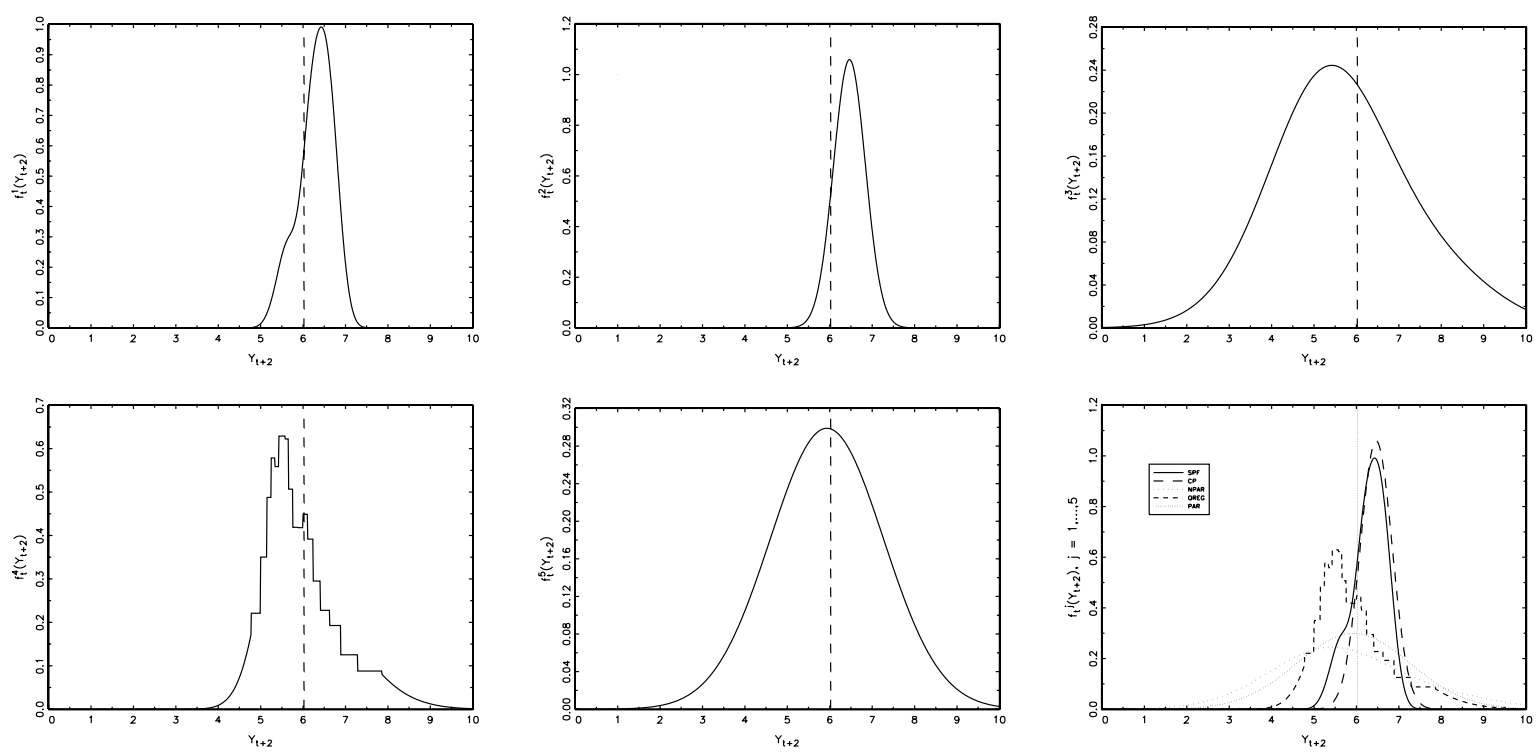

Figure 2: Comparison of five predictive densities $f_{t}^{j}\left(Y_{t+2}\right), j=1, \ldots, 5$, with $Y_{t+2}$ representing the TBILL rate in the fourth quarter of 2000. The first row displays the survey-based predictive densities constructed from the SPF/ZEW data $(j=1,2)$ as well as the nonparametric predictive density $(j=3)$. The second row displays the quantile regression based- and parametric predictive densities $(j=4,5)$, as well as a joint graph of all five alternatives. The vertical line marks $y_{t+2}$, the TBILL rate which actually materialized in 2000/4. 

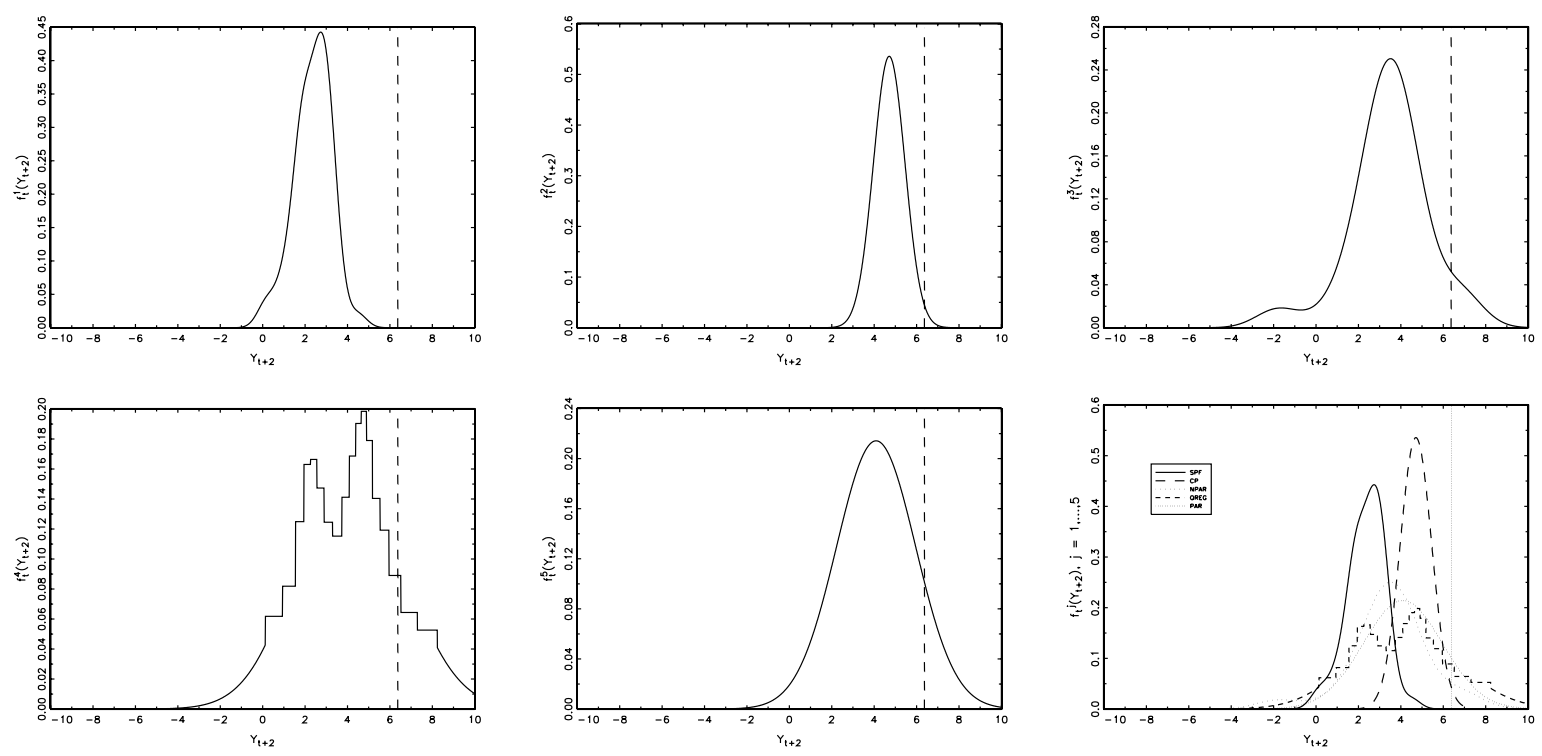

Figure 3: Comparison of five predictive densities $f_{t}^{j}\left(Y_{t+2}\right), j=1, \ldots, 5$, with $Y_{t+2}$ representing the annualized CPI inflation rate during the third quarter of 2008. The first row displays the survey-based predictive densities constructed from the SPF/ZEW data $(j=1,2)$ as well as the nonparametric predictive density $(j=3)$. The second row displays the quantile regression based- and parametric predictive densities $(j=4,5)$, as well as a joint graph of all five alternatives. The vertical line marks $y_{t+2}$, the annualized CPI inflation rate which actually materialized in 2008/3.

\section{Empirical Results}

The log scores for all five individual predictive densities and the four different weighting schemes are presented in Table 1. The associated scatter plot:15 are depicted in Figure 4 ,

A first important observation is that the equally weighted mixture combination performs very well relative to all other individual and combined predictive densities. For the CPI inflation- and TBILL rate series, the equally weighted combination scheme outperforms all competitors in terms of average log score over the evaluation period. For the two other series, it performs only marginally worse than the best competitor. In terms of the Superior Predictive Ability (SPA) test by Hansen (2005), there is no evidence that the equally weighted scheme is dominated by a competitor at any conventional level of significance; this is true for all four time series. The performance of the other three combination schemes is somewhat instable across the four series. While OIS weights perform quite satisfactory, both recursive weighting schemes (RLS and RB) yield considerably worse results. This suggests that relative model performance can hardly be predicted. Our finding that simple equal weights perform quite well mirrors a stylized fact from the literature on combinations of point forecasts (the "forecast combination puzzle"), that simple averages across all pre-

\footnotetext{
${ }^{15}$ We omit the three weighting schemes other than equal weights for ease of presentation.
} 
dictions are often superior to more sophisticated specifications of the weights assigned to the individual forecasts; see Jose and Winkler (2008) 16 In this literature, Smith and Wallis (2009) suggest that involved specifications of the combination weights produce estimation noise which increases the variance of the resulting combined forecast, to an extent which dominates potential bias reductions through flexible weights. Our results, as well as results by Geweke and Amisano (2011), suggest that the "forecast combination puzzle" seems to apply also to combinations of predictive densities 17 In the light of these results, we focus on the equally weighted combination scheme in the following.

\begin{tabular}{|l|r|r||r|r||r|r||r|r|}
\hline & \multicolumn{2}{|c||}{ GDP growth } & \multicolumn{2}{c||}{ CPI inflation } & \multicolumn{2}{c||}{ TBILL } & \multicolumn{2}{c|}{ TBOND } \\
& MLS & \multicolumn{1}{|c|}{ SPA } & MLS & SPA & MLS & SPA & MLS & SPA \\
\hline SPF & -7.11 & 1.91 & -7.95 & 7.54 & -6.62 & 6.06 & -1.97 & 12.41 \\
CP & -30.14 & 0.09 & -23.05 & 0.03 & -4.91 & 1.74 & -1.26 & 20.89 \\
NPAR & -2.59 & 79.54 & -2.94 & 54.17 & -1.84 & 0.00 & -1.60 & 0.00 \\
QREG & -2.60 & 62.26 & -2.79 & 28.25 & -1.85 & 8.58 & -1.91 & 14.88 \\
PAR & -2.69 & 6.61 & -2.97 & 14.52 & -1.60 & 6.90 & -1.08 & 57.95 \\
\hline E & -2.59 & 70.20 & -2.49 & 99.34 & -1.20 & 83.73 & -1.02 & 96.94 \\
RLS & -2.58 & 97.17 & -2.90 & 44.69 & -1.88 & 7.40 & -1.09 & 46.45 \\
RB & -2.62 & 31.37 & -3.07 & 19.67 & -1.91 & 9.87 & -1.08 & 64.72 \\
OIS & -2.61 & 72.40 & -2.78 & 41.20 & -1.29 & 32.66 & -1.02 & 95.11 \\
\hline
\end{tabular}

Table 1: Results of two-step ahead density forecasts for the evaluation period 2000/2 to 2009/4 (39 quarterly data points). Mean log scores (MLS; first column) are defined as MLS $\equiv \frac{1}{39} \sum_{t=T_{c}}^{T-2} \ln \left(\tilde{f}_{t}\left(y_{t+2}\right)\right)$, where $\tilde{f}_{t}(\cdot)$ is a generic two-step ahead predictive density. $T_{c}$ and $T$ correspond to 1999/4 and 2009/2, respectively. P-values of the Superior Predictive Ability test of Hansen (2005) (SPA; second column; values in percent) refer to the null hypothesis that a particular model is not dominated by any competitor. The relevant loss function is the negative of the $\log$ score. Following Hansen and Lunde (2005), we use a block length parameter of $q=0.5$ and a sample size of $B=10000$ in our bootstrap implementation.

\footnotetext{
${ }^{16}$ Interestingly, DeMiguel, Garlappi, and Uppal (2009) obtain very similar results in the context of choosing portfolio weights.

${ }^{17}$ Geweke and Amisano (2011, p.10) report that even with hundreds of daily stock return observations, it is challenging to beat a simple equally weighted mixture model.
} 
GDP

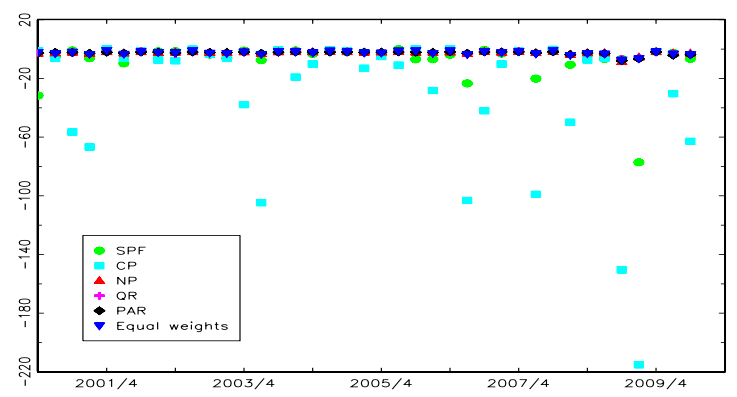

TBILL

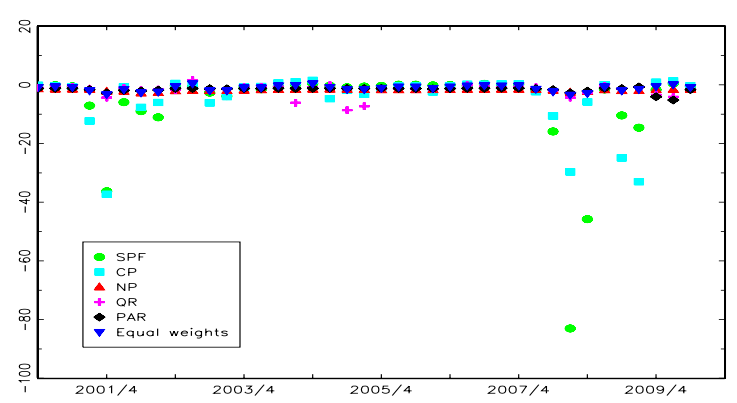

CPI

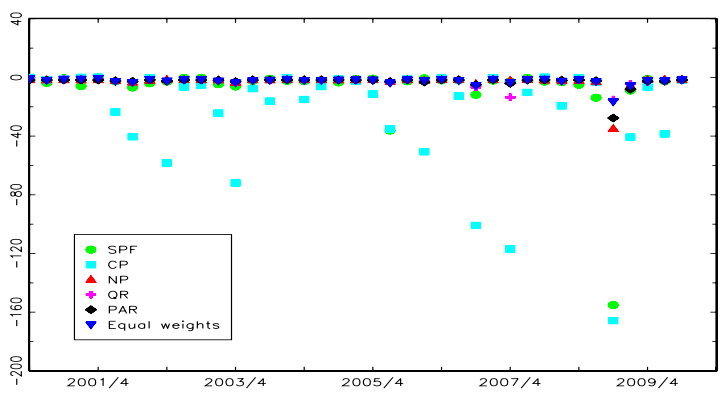

TBOND

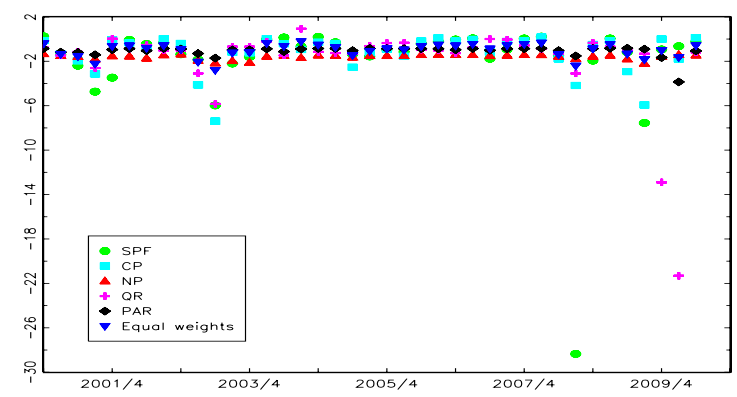

Figure 4: Scatter plots of log scores for two-quarter ahead predictive densities: Annualized growth rate of real GDP, annualized CPI inflation rate, ten-year TBOND rate and three-month TBILL rate. The evaluation period ranges from 2000/2 - 2009/4 (39 quarterly data points).

A second important observation is that the individual survey models perform poorly in terms of the log score. The two survey-based predictive densities are clearly inferior to the time series specifications we consider. For the ZEW-based density, the null hypothesis of the SPA test is rejected at the $5 \%$ level for all time series except TBOND. Similarly, for the SPF-based density and all series except TBOND, the SPA null hypothesis is rejected at the $5 \%$ or $10 \%$ levels. The poor average performance of the two survey densities is due to the fact that they are too narrow; this causes some realizations to fall far into the tails of their support which results in very low values of the log score criterion (again see Figure 4). For most points in our evaluation sample, one of the two survey densities constitutes the worst model (see Table 21). Thus in general, the estimated cross-sectional distribution of point forecasts appears to be an inappropriate predictive distribution. This confirms and generalizes the findings of Lahiri and Sheng (2010) and Boero, Smith, and Wallis (2008) who show that cross-sectional disagreement tends to understate (their measures of) predictive uncertainty. Note, however, that Bomberger (1996) suggests that disagreement tracks uncertainty only up to a factor of proportionality. 


\begin{tabular}{|l|r|r||r|r||r|r||r|r|}
\hline & \multicolumn{2}{|c||}{ GDP growth } & \multicolumn{2}{c||}{ CPI inflation } & \multicolumn{2}{c||}{ TBILL } & \multicolumn{2}{c|}{ TBOND } \\
& \% best & \% worst & \% best & \% worst & \% best & \% worst & \% best & \% worst \\
\hline SPF & 23.1 & 17.9 & 23.1 & 30.8 & 28.2 & 15.4 & 30.8 & 25.6 \\
CP & 28.2 & 59.0 & 28.2 & 59.0 & 35.9 & 23.1 & 17.9 & 15.4 \\
NPAR & 28.2 & 0.0 & 35.6 & 0.0 & 5.1 & 46.2 & 0.0 & 53.8 \\
QREG & 7.7 & 5.1 & 12.8 & 2.6 & 15.4 & 10.3 & 28.2 & 5.1 \\
PAR & 12.8 & 17.9 & 10.3 & 7.7 & 15.4 & 5.1 & 23.1 & 0.0 \\
\hline
\end{tabular}

Table 2: Relative performance of the five individual predictive densities during our evaluation period 2000/2 to 2009/4 (39 quarterly data points): "\% best" denotes the share among 39 evaluation points for which a particular density achieved the highest log score, and analogously for "\% worst".

A third important observation is that the individual survey models, although they perform poorly in terms of the log score and often constitute the worst models, are also the best forecasting models for a considerable share of evaluation points (between $17.9 \%$ and $35.9 \%$; see Table 2). This suggests that the estimated cross-sectional distributions of point forecasts may still contain valuable information, although they are exceedingly risky when used individually.

\begin{tabular}{|l|r|r||r|r||r|r||r||r|}
\hline & \multicolumn{2}{|c||}{ GDP growth } & \multicolumn{2}{c||}{ CPI inflation } & \multicolumn{2}{c||}{ TBILL } & \multicolumn{2}{c|}{ TBOND } \\
& DMLS & DM stat & DMLS & DM stat & DMLS & DM stat & DMLS & DM stat \\
\hline TS vs. (TS + SPF + CP) & -0.00 & -0.08 & -0.01 & -0.16 & -0.30 & $-1.98^{*}$ & -0.15 & $-2.24^{*}$ \\
\hline TS vs. (TS + SPF $)$ & -0.00 & -0.04 & 0.00 & -0.17 & -0.17 & $-1.80^{*}$ & -0.11 & $-2.22^{*}$ \\
\hline TS vs. $(\mathrm{TS}+\mathrm{CP})$ & 0.01 & 0.13 & 0.02 & 0.27 & -0.28 & $-2.12^{*}$ & -0.11 & $-2.59^{* *}$ \\
\hline
\end{tabular}

Table 3: Comparisons of equally weighted density combinations with- and without survey information during our evaluation period 2000/2 to 2009/4 (39 quarterly data points). "DMLS" denotes the mean $\log$ score of combination A minus the mean log score of combination B. "DM stat" gives the DieboldMariano test statistic corresponding to the null hypothesis that including survey information improves the expected log score of the combination. The test statistic is computed from an auxiliary regression of the $\log$ score differential on a constant, using HAC standard errors. The t-statistic associated with the constant yields the Diebold-Mariano test statistic. One- and two stars indicate significance at the five percent- and one percent levels (one-sided tests).

In Table 3 we report our main results of whether or not the inclusion of the survey based densities significantly improves the log score criterion and hence helps to construct a predictive density that is closer to the true one. We differentiate between including both- or either of the two survey based densities to the pool of three time series based densities. Throughout, we focus on equally weighted combinations of all involved models. We report DM test statistics for mixture combinations with- and without the survey information in Table 3, For the GDP growth- and CPI inflation series, including or excluding the survey 
based densities does not make a significant difference. In contrast, including (either one or both of) the survey densities significantly improves upon an equally weighted pool of the three time series models for the TBILL- and TBOND series. The corresponding DM test statistics are significant at the $5 \%$ and $1 \%$ levels (one-sided tests).

These results suggest that although the cross-sectional distributions of point forecasts perform very poorly individually, they contain substantial information which can be exploited, for example via simple equally weighted combinations. Hence, suggestions to dismiss information in cross-sections of point forecasts altogether (e.g. Engelberg, Manski, and Williams (2009)) might be overhasty. This is particularly true since the existing literature tends to focus on disagreement as one specific characteristic of the cross-sectional distribution of point forecasts. The more general question "What is and how do we construct the true predictive density?" has rarely been asked.

\section{Conclusion}

Measures of disagreement and predictive uncertainty prevalent in the literature are subject to fundamental statistical critique. Both conceptual and practical issues arise. We suggest that the focus of attention should be shifted to the true predictive density, which would naturally overcome the above ambiguities. Hence we present a combination approach in which models relying on distinct information sets and functional form assumptions are combined to approximate the true predictive density. Within this framework we ask the important question whether cross-sections of survey point forecasts reveal information about this density. This question generalizes the debate about disagreement versus uncertainty.

We consider cross-sectional distributions of survey point forecasts from the SPF and the ZEW for GDP growth, inflation, the TBILL rate and the TBOND rate in the US. Individually, both distributions perform poorly for all variables. Nevertheless, we show that their inclusion significantly improves the quality of combined predictive densities for the TBILL and TBOND rates while it does not affect the quality of the combination for GDP growth and CPI inflation. These results suggest that information in cross-sections of point forecasts should not be excluded a priori when considering measures of predictive uncertainty.

More generally, we find that combining predictive densities is a successful strategy in that combinations can considerably improve upon all of their components. The stable combination schemes we consider (in particular, equal weights) effectively exploit information from predictive densities which are inappropriate when considered in isolation. In contrast, 
we find little support for combination mechanisms which aim at recursively selecting the best individual models. This suggests that relative model performance is hard to predict in our application. However, further research is needed in order to fully understand the nature of optimal combinations of predictive densities. Work along the lines of Geweke and Amisano (2011) and Clements and Harvey (2011), who consider the case of a binary response variable, promises to yield important insights in this respect. 


\section{References}

Aiolfi, M., C. Capistrán, and A. Timmermann (2011): "Forecast Combinations," in Oxford Handbook of Economic Forecasting, ed. by M. P. Clements, and D. F. Hendry, pp. 355-390. Oxford University Press.

Bao, Y., T.-H. Lee, and B. Saltoglu (2007): "Comparing Density Forecast Models," Journal of Forecasting, 26, 203-225.

Boero, G., J. Smith, and K. F. Wallis (2008): "Uncertainty and Disagreement in Economic Prediction: The Bank of England Survey of External Forecasters," Economic Journal, 118, 1107-1127.

(2010): "Scoring Rules and Survey Density Forecasts," International Journal of Forecasting, 27, 379-393.

Bomberger, W. A. (1996): "Disagreement as a Measure of Uncertainty," Journal of Money, Credit and Banking, 28, 381-392.

Carlson, J. A., And M. Parkin (1975): "Inflation Expectations," Economica, 42, 123138.

Cenesizoglu, T., and A. Timmermann (2008): "Is the Distribution of Stock Returns Predictable?," Working Paper, University of California at San Diego.

Clements, M., and D. I. Harvey (2011): "Combining Probability Forecasts," International Journal of Forecasting, 27, 208-223.

Coroneo, L., and D. Veredas (2010): "A Simple Two-Component Model for the Distribution of Intraday Returns," European Journal of Finance, forthcoming.

Demiguel, V., L. Garlappi, and R. Uppal (2009): "Optimal Versus Naive Diversification: How Inefficient is the 1/N Portfolio Strategy?," Review of Financial Studies, 22(5), 1915-1953.

Dette, H., N. Neumeyer, And K. F. Pilz (2006): “A Simple Nonparametric Estimator of a Strictly Monotone Regression Function," Bernoulli, 12, 469-490.

Dette, H., and S. Volgushev (2008): "Non-Crossing Non-Parametric Estimates of Quantile Curves," Journal of the Royal Statistical Society, Series B, 70, 609-627.

Diebold, F. X., and R. S. Mariano (1995): "Comparing Predictive Accuracy," Journal of Business \& Economic Statistics, 13, 253-263. 
Engelberg, J., C. F. Manski, and J. Williams (2009): "Comparing the Point Predictions and Subjective Probability Distributions of Professional Forecasters," Journal of Business \&5 Economic Statistics, 27, 30-41.

Geweke, J., And G. Amisano (2011): "Optimal Prediction Pools," Journal of Econometrics, 164, 130-141.

Giordani, P., And P. SÖDERlind (2003): "Inflation Forecast Uncertainty," European Economic Review, 47, 1037-1059.

Gneiting, T., And A. E. Raftery (2007): "Strictly Proper Scoring Rules, Prediction, and Estimation," Journal of the American Statistical Association, 102, 359-378.

Good, I. (1952): "Rational Decisions," Journal of the Royal Statistical Society, Series B, $14,107-114$.

Hall, S. G., and J. Mitchell (2007): "Combining Density Forecasts," International Journal of Forecasting, 23, 1-13.

Hansen, P. R. (2005): "A Test for Superior Predictive Ability," Journal of Business E6 Economic Statistics, 23, 365-380.

Hansen, P. R., And A. Lunde (2005): "A Forecast Comparison of Volatility Models: Does Anything Beat a GARCH(1,1)?," Journal of Applied Econometrics, 20, 873-889.

Härdle, W., M. Müller, S. Sperlich, And A. Werwatz (2004): Nonparametric and Semiparametric Models. Springer.

Jore, A. S., J. Mitchell, and S. P. Vahey (2010): "Combining Forecast Densities from VARs with Uncertain Instabilities," Journal of Applied Econometrics, 25, 621-634.

Jose, V. R. R., And R. L. Winkler (2008): "Simple Robust Averages of Forecasts: Some Empirical Results," International Journal of Forecasting, 24(1), 163 - 169.

Kascha, C., and F. Ravazzolo (2010): “Combining Inflation Density Forecasts," Journal of Forecasting, 29, 231-250.

Koenker, R. (2005): Quantile Regression. Cambridge University Press.

Komunjer, I. (2005): "Quasi-Maximum Likelihood Estimation for Conditional Quantiles," Journal of Econometrics, 128, 137-164.

Kullback, S., And R. A. Leibler (1951): "On Information and Sufficiency," The Annals of Mathematical Statistics, 22, 79-86. 
Lahiri, K., and X. Sheng (2010): "Measuring Forecast Uncertainty by Disagreement: The Missing Link," Journal of Applied Econometrics, 25, 514-538.

Mankiw, N. G., R. Reis, and J. Wolfers (2003): "Disagreement about Inflation Expectations," NBER Macroeconomics Annual, 18, 209-248.

Manski, C. F. (2004): "Measuring Expectations," Econometrica, 72, 1329-1376.

Nolte, I., S. Nolte, And W. Pohlmeier (2010): "The Good, the Bad and the Ugly: Analyzing Forecasting Behavior within a Quantal Response Framework with Misclassification," Working Paper, Warwick Business School.

Nolte, I., And W. Pohlmeier (2007): "Using Forecasts of Forecasters to Forecast," International Journal of Forecasting, 23(1), 15 - 28.

Pesaran, M. H., and M. Weale (2006): "Survey Expectations," in Handbook of Economic Forecasting, ed. by G. Elliott, C. W. Granger, and A. Timmermann. Elsevier.

Rubinstein, R. Y., And D. P. Kroese (2008): Simulation and the Monte Carlo Method. Wiley-Interscience, 2 edn.

Silverman, B. W. (1986): Density Estimation for Statistics and Data Analysis. Chapman \& Hall.

Smith, J., And K. F. Wallis (2009): "A Simple Explanation of the Forecast Combination Puzzle," Oxford Bulletin of Economics and Statistics, 71, 331-355.

Stock, J., and M. W. Watson (2002): "Forecasting Using Principal Components From a Large Number of Predictors," Journal of the American Statistical Association, 97, $1167-1179$.

Timmermann, A. (2006): "Forecast Combinations," in Handbook of Economic Forecasting, ed. by G. Elliott, C. W. Granger, and A. Timmermann. Elsevier.

Wallis, K. F. (2005): "Combining Density and Interval Forecasts: A Modest Proposal," Oxford Bulletin of Economics and Statistics, 67, 983-994.

WinkleR, R. L. (1969): "Scoring Rules and the Evaluation of Probability Assessors," Journal of the American Statistical Association, 64, 1073-1078.

(1996): "Scoring Rules and the Evaluation of Probabilities," TEST, 5(1), 1-26.

Zarnowitz, V. A., and L. A. Lambros (1987): "Consensus and Uncertainty in Economic Prediction," Journal of Political Economy, 95, 591-621. 


\section{Data Appendix}

\begin{tabular}{|l|}
\hline Series name \\
\hline Real Gross Domestic Product \\
\hline Real Personal Consumption Expenditures \\
\hline Real Personal Consumption Expenditures: Durable Goods \\
\hline Real Personal Consumption Expenditures: Nondurable Goods \\
\hline Real Personal Consumption Expenditures: Services \\
\hline Real Gross Private Domestic Investment \\
\hline Real Private Fixed Investment \\
\hline Real Private Nonresidential Fixed Investment \\
\hline Real Nonresidential Investment: Equipment \& Software \\
\hline Real Private Residential Fixed Investment \\
\hline Real Exports of Goods \& Services \\
\hline Real Imports of Goods \& Services \\
\hline Real Government Consumption Expenditures \& Gross Investment \\
\hline Real Federal Consumption Expenditures \& Gross Investment \\
\hline Real State \& Local Consumption Expenditures \& Gross Investment \\
\hline Industrial Production Index \\
\hline Industrial Production: Final Products (Market Group) \\
\hline Industrial Production: Consumer Goods \\
\hline Industrial Production: Durable Consumer Goods \\
\hline Industrial Production: Nondurable Consumer Goods \\
\hline Industrial Production: Business Equipment \\
\hline Industrial Production: Materials \\
\hline Industrial Production: Durable Materials \\
\hline Industrial Production: nondurable Materials \\
\hline All Employees: Total Private Industries \\
\hline All Employees: Goods-Producing Industries \\
\hline All Employes: Natural Resources \& Mining \\
\hline All Employees: Construction \\
\hline All Employees: Durable Goods Manufacturing \\
\hline All Employees: Nondurable Goods Manufacturing \\
\hline All Employees: Service-Providing Industries \\
\hline All Employes: Trade, Transportation \& Utilities \\
\hline All Employees: Wholesale Trade \\
\hline All Employees: Retail Trade \\
\hline All Employees: Financial Activities \\
\hline All Employees: Government \\
\hline Civilian Labor Force \\
\hline Nonfarm Business Sector: Hours of All Persons \\
\hline Average Weekly Hours: Manufacturing \\
\hline Average Weekly Hours: Overtime: Manufacturing \\
\hline \\
\hline
\end{tabular}

\begin{tabular}{|c|c|c|}
\hline Code & Description & \\
\hline GDPC96 & Billions of Chained 2005 Dollars, Quarterly, Seasonally Adjusted Annual Rate & \\
\hline & Billions of Chained 2005 Dollars, Quarterly, Seasonally Adjusted Annual Rate & \\
\hline PCDGCC96 & Billions of Chained 2005 Dollars, Quarterly, Seasonally Adjusted Annual Rate & \\
\hline PCNDGC96 & Billions of Chained 2005 Dollars, Quarterly, Seasonally Adjusted Annual Rate & $\mathrm{D}$ \\
\hline PCESVC96 & Billions of Chained 2005 Dollars, Quarterly, Seasonally Adjusted Annual Rate & \\
\hline GPDIC96 & Billions of Chained 2005 Dollars, Quarterly, Seasonally Adjusted Annual Rate & \\
\hline FPIC96 & Billions of Chained 2005 Dollars, Quarterly, Seasonally Adjusted Annual Rate & \\
\hline PNFIC96 & Billions of Chained 2005 Dollars, Quarterly, Seasonally Adjusted Annual Rate & $\mathrm{D}$ \\
\hline NRIPDC96 & Billions of Chained 2005 Dollars, Quarterly, Seasonally Adjusted Annual Rate & \\
\hline PRFIC96 & Billions of Chained 2005 Dollars, Quarterly, Seasonally Adjusted Annual Rate & $\bar{D}$ \\
\hline EXPGSC96 & Billions of Chained 2005 Dollars, Quarterly, Seasonally Adjusted Annual Rate & \\
\hline IMPGSC96 & Billions of Chained 2005 Dollars, Quarterly, Seasonally Adjusted Annual Rate & \\
\hline GCEC96 & Billions of Chained 2005 Dollars, Quarterly, Seasonally Adjusted Annual Rate & $\mathrm{D}$ \\
\hline FGCEC96 & Billions of Chained 2005 Dollars, Quarterly, Seasonally Adjusted Annual Rate & $\bar{D}$ \\
\hline & Billions of Chained 2005 Dollars, Quarterly, Seasonally Adjusted Annual Rate & \\
\hline INDPRO & Index 2002 $=100$, Monthly, Seasonally Adjusted & $\bar{D}$ \\
\hline IPFINAL & Index $2002=100$, Monthly, Seasonally Adjusted & $\overline{\mathrm{D}}$ \\
\hline IPCONGD & Index $2002=100$, Monthly, Seasonally Adjusted & $\mathrm{D}$ \\
\hline & Index $2002=100$, Monthly, Seasonally Adjusted & \\
\hline IPNC & Index $2002=100$, Monthly, Seasonally Adjusted & $\bar{D}$ \\
\hline$\overline{\mathrm{IPBC}}$ & Index $2002=100$, Monthly, Seasonally Adjusted & $\mathrm{D}$ \\
\hline$\overline{\mathrm{IPM}}$ & Index $2002=100$, Monthly, Seasonally Adjusted & $\mathrm{D}$ \\
\hline & $02=100$, Monthly, Seasonally Adjusted & \\
\hline$\overline{\mathrm{IPN}}$ & Index $2002=100$, Monthly, Seasonally Adjusted & $\bar{D}$ \\
\hline$\overline{\mathrm{USP}}$ & Thousands, Monthly, Seasonally Adjusted & \\
\hline USC & Thousands, Monthly, Seasonally Adjusted & $\mathrm{D}$ \\
\hline$\overline{\text { USI }}$ & onthly, Seasonally Ad & \\
\hline USC & Thousands, Monthly, Seasonally Adjusted & $\mathrm{D}$ \\
\hline & Thousands, Monthly, Seasonally Adjusted & \\
\hline NDMANEMP & Thousands, Monthly, Seasonally Adjusted & $\mathrm{D}$ \\
\hline SRVPRD & Thousands, Monthly, Seasonally Adjus & \\
\hline & ly, Seasonally Adj & $\bar{D}$ \\
\hline USWTRADE & Thousands, Monthly, Seasonally Adjusted & $\mathrm{D}$ \\
\hline USTRADE & Thousands, Monthly, Seasonally Adjusted & $\mathrm{D}$ \\
\hline$\overline{\text { USF }}$ & Thousands, Monthly, Seasonally Adjusted & \\
\hline & ly, Seasonally Adjusted & $\mathrm{D}$ \\
\hline CLF16OV & Thousands, Monthly, Seasonally Adjusted & $\bar{D}$ \\
\hline HOANBS & Index $1992=100$, Quarterly, Seasonally Adjusted & $\mathrm{D}$ \\
\hline & & \\
\hline AWOTMAN & Hours, Monthly, Seasonally Adjusted & \\
\hline
\end{tabular}

Table 4: Series used for construction of the principal component $p c_{t}$ appearing in models four and five above. All series have been downloaded from the FRED database administered by the Federal Reserve of St. Louis; the corresponding (FRED-internal) series codes are listed in the second column. Data transformations A - E ("Tf", fourth column) are defined in Table 5 below. 


\begin{tabular}{|l|l}
\hline Series name & \\
\hline Civilian Unemployment Rate & \\
\hline Average (Mean) Duration of Unemployment & \\
\hline Civilians Unemployed - Less Than 5 Weeks & \\
\hline Civilian Unemployed for 5-14 Weeks & \\
\hline Civilians Unemployed - 15 Weeks \& Over & \\
\hline Civilians Unemployed for 15-26 Weeks & \\
\hline Civilians Unemployed for 27 Weeks and Over & \\
\hline Civilian Participation Rate & \\
\hline Housing Starts: Total: New Privately Owned Housing Units Started & \\
\hline New Private Housing Units Authorized by Building Permit & \\
\hline Housing Starts in Northeast Census Region & \\
\hline Housing Starts in Midwest Census Region & \\
\hline Housing Starts in South Census Region & \\
\hline Housing Starts in West Census Region & \\
\hline ISM Manufacturing: PMI Composite Index & \\
\hline ISM Manufacturing: New Orders Index & \\
\hline SSM Manufacturing: Supplier Deliveries Index & \\
\hline ISM Manufacturing: Inventories Index & \\
\hline Gross Domestic Product: Chain-type Price Index & \\
\hline Personal Consumption Expenditures: Chain-type Price Index & \\
\hline Consumer Price Index For All Urban Consumers: All Items & \\
\hline Personal Consumption Expenditures: Chain-Type Price Index Less Food and Energy & \\
\hline Consumer Price Index for All Urban Consumers: All Items Less Food \& Energy & CP \\
\hline Consumer Price Index for All Urban Consumers: Food & \\
\hline Consumer Price Index for All Urban Consumers: Apparel & \\
\hline Consumer Price Index for All Urban Consumers: Energy & \\
\hline Consumer Price Index for All Urban Consumers: Transportation & \\
\hline Consumer Price Index for All Urban Consumers: Medical Care & \\
\hline Gross Private Domestic Investment: Chain-type Price Index & \\
\hline Spot Oil Price: West Texas Intermediate & \\
\hline Average Hourly Earnings: Construction & \\
\hline Average Hourly Earnings: Manufacturing & \\
\hline Business Sector: Output Per Hour of All Persons & \\
\hline Nonfarm Business Sector: Real Compensation Per Hour & \\
\hline Nonfarm Business Sector: Unit Labor Cost & \\
\hline Effective Federal Funds Rate & \\
\hline 3-Month Treasury Bill: Secondary Market Rate & \\
\hline 5-Year Treasury Constant Maturity Rate & \\
\hline 10-Year Treasury Constant Maturity Rate & \\
\hline
\end{tabular}

\begin{tabular}{|c|c|c|}
\hline Code & Description & Tf \\
\hline UNRATE & Percent, Monthly, Seasonally Adjusted & \\
\hline UEMPMEAN & Weeks, Monthly, Seasonally Adjusted & \\
\hline UEMPLT5 & Thousands, Monthly, Seasonally Adjusted & $\overline{\mathrm{D}}$ \\
\hline UEMP5TO14 & Thousands, Monthly, Seasonally Adjusted & $\mathrm{D}$ \\
\hline UEMP15OV & Thousands, Monthly, Seasonally Adjusted & \\
\hline UEMP15T26 & 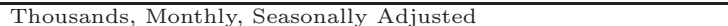 & $\overline{\mathrm{D}}$ \\
\hline UEMP27OV & Thousands, Monthly, Seasonally Adjusted & $\bar{D}$ \\
\hline CIVPART & Percent, Monthly, Seasonally Adjusted & \\
\hline HOUST & Thousands of Units, Monthly, Seasonally Adjusted Annual Rate & \\
\hline$\overline{\text { PERMIT }}$ & Thousands of Units, Monthly, Seasonally Adjusted Annual Rate & 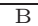 \\
\hline HOUSTNE & Thousands of Units, Monthly, Seasonally Adjusted Annual Rate & $\mathrm{B}$ \\
\hline HOUSTMW & Thousands of Units, Monthly, Seasonally Adjusted Annual Rate & $\mathrm{B}$ \\
\hline HOUSTS & Thousands of Units, Monthly, Seasonally Adjusted Annual Rate & \\
\hline HOUSTW & Thousands of Units, Monthly, Seasonally Adjusted Annual Rate & $\mathrm{B}$ \\
\hline NAPM & Index, Monthly, Seasonally Adjusted & $\mathrm{A}$ \\
\hline NAPMNOI & Index, Monthly, Seasonally Adjusted & $\mathrm{A}$ \\
\hline NAPMSDI & Index, Monthly, Seasonally Adjusted & A \\
\hline NAPMII & Index, Monthly, Seasonally Adjusted & $\mathrm{A}$ \\
\hline GDPCTPI & Index $2005=100$, Quarterly, Seasonally Adjusted & $\mathrm{E}$ \\
\hline PCECTPI & Index $2005=100$, Quarterly, Seasonally Adjusted & $\mathrm{E}$ \\
\hline CPIAUCSL & Index 1982-84=100, Monthly, Seasonally Adjusted & $\mathrm{E}$ \\
\hline PCEPILFE & Index 2005=100, Monthly, Seasonally Adjusted & $\mathrm{E}$ \\
\hline CPILFESL & Index 1982-84=100, Monthly, Seasonally Adjusted & $\mathrm{E}$ \\
\hline CPIUFDSL & Index 1982-84=100, Monthly, Seasonally Adjusted & $\mathrm{E}$ \\
\hline CPIAPPSL & Index 1982-84=100, Monthly, Seasonally Adjusted & \\
\hline CPIENGSL & Index 1982-84=100, Monthly, Seasonally Adjusted & $\mathrm{E}$ \\
\hline CPITRNSL & Index 1982-84=100, Monthly, Seasonally Adjusted & $\mathrm{E}$ \\
\hline CPIMEDSL & Index 1982-84=100, Monthly, Seasonally Adjusted & $\mathrm{E}$ \\
\hline GPDICTPI & Index $2005=100$, Quarterly, Seasonally Adjusted & \\
\hline OILPRICE & Dollars per Barrel, Monthly & $\frac{D}{D}$ \\
\hline AHECONS & Dollars per Hour, Monthly & $\bar{D}$ \\
\hline AHEMAN & Dollars per Hour, Monthly & $\mathrm{D}$ \\
\hline OPHPBS & Index 1992=100, Quarterly, Seasonally Adjusted & $\overline{\mathrm{D}}$ \\
\hline COMPRNFB & Index 1992=100, Quarterly, Seasonally Adjusted & $\bar{D}$ \\
\hline ULCNFB & Index $1992=100$, Quarterly, Seasonally Adjusted & \\
\hline FF & Percent, Weekly Ending Wednesday & $\mathrm{C}$ \\
\hline WTB3MS & Percent,Weekly Ending Friday & $\mathrm{C}$ \\
\hline WGS5YR & Percent,Weekly Ending Friday & \\
\hline WGS10YR & Percent,Weekly Endi & \\
\hline
\end{tabular}

Table 4 (cont'd): Series used for construction of the principal component $p c_{t}$ appearing in models four and five above. All series have been downloaded from the FRED database administered by the Federal Reserve of St. Louis; the corresponding (FRED-internal) series codes are listed in the second column. Data transformations A - E ("Tf", fourth column) are defined in Table 5 below. 


\begin{tabular}{|l|l|l|}
\hline Series name & Code & Description \\
\hline Moody's Seasoned Aaa Corporate Bond Yield & WAAA & Percent,Weekly Ending Friday \\
\hline Moody's Seasoned Baa Corporate Bond Yield & C \\
\hline WGS10YR - WTB3MS & WBAA & Percent,Weekly Ending Friday \\
\hline WAAA - WGS10YR & - & C \\
\hline WBAA - WGS10YR & - & Percent, Weekly Ending Friday \\
\hline Dow Jones Industrial* & Percent, Weekly Ending Friday \\
\hline Consumer Confidence* & S19655 & Index, Daily \\
\hline Real Estate Loans at All Commercial Banks & 440005021 & Index, Monthly, Seasonally Adjusted \\
\hline Consumer (Individual) Loans at All Commercial Banks & REALLN & Billions of Dollars, Monthly, Seasonally Adjusted \\
\hline Commercial and Industrial Loans at All Commercial Banks & CONSUMER & Billions of Dollars, Monthly, Seasonally Adjusted \\
\hline M1 Money Stock & BUSLOANS & Billions of Dollars, Monthly, Seasonally Adjusted \\
\hline M2 Money Stock & M1SL & Billions of Dollars, Monthly, Seasonally Adjusted \\
\hline Bank Prime Loan Rate & A \\
\hline
\end{tabular}

Table 4 (cont'd): Series used for construction of the principal component $p c_{t}$ appearing in models four and five above. Series not marked with * have been downloaded from the FRED database administered by the Federal Reserve of St. Louis; the corresponding (FRED-internal) series codes are listed in the second column. Series marked with * have been downloaded from data stream; here the second column displays the data stream series code. Data transformations A - E ("Tf", fourth column) are defined in Table 5 below.

\begin{tabular}{|c|c|}
\hline Code & Transformation (Tf) \\
\hline A & $Y_{t}$ \\
B & $\ln \left(Y_{t}\right)$ \\
C & $Y_{t}-Y_{t-1}$ \\
D & $\ln \left(Y_{t}\right)-\ln \left(Y_{t-1}\right)$ \\
E & $\ln \left(\frac{Y_{t}}{Y_{t-1}}\right)-\ln \left(\frac{Y_{t-1}}{Y_{t-2}}\right)$ \\
\hline
\end{tabular}

Table 5: Data Transformations A - E used in Table 4 above. $Y_{t}$ denotes the original value of the series. 